\title{
THE ELECTROCHEMICAL PROPERTIES OF FOUR DENTAL CASTING SUPRASTRUCTURE ALLOYS COUPLED WITH TITANIUM IMPLANTS
}

\author{
Suleyman Hakan TUNA ${ }^{1}$, Nuran OZCICEK PEKMEZ ${ }^{2}$, Filiz KEYF ${ }^{3}$, Fulya CANLi ${ }^{4}$
}

\begin{abstract}
1- DDS, PhD, Department of Prosthodontics, Faculty of Dentistry, Suleyman Demirel University, Isparta, Turkey.
2- PhD, Professor, Department of Chemistry, Faculty of Science, Hacettepe University, Ankara, Turkey.

3- DDS, PhD, Professor, Department of Prosthodontics, Faculty of Dentistry, Hacettepe University, Ankara, Turkey.

4- Research assistant, Department of Chemistry, Faculty of Science, Hacettepe University, Ankara, Turkey.
\end{abstract}

Corresponding address: Dr. Suleyman Hakan Tuna - Suleyman Demirel Universitesi, Dis Hekimligi Fakultesi, Protetik Dis Ted. A.D Cunur, Isparta, Turkey. Phone: +90 246 2113234. Fax: - +90 246 2370607- e-mail: shtuna@hotmail.com

Received: July 24, 2008 - Accepted: February 12, 2009

\begin{abstract}
$O$ bjectives: As the choice of suprastructure alloy to be combined with titanium for the oral cavity is still a much debated issue, the aim of this study was to investigate the electrochemical interaction of the suprastructure/implant couples under the determined experiment conditions. Material and Methods: The potentiodynamic polarization curves and open-circuit potentials (OCP) of four UCLA type suprastructures coupled with straight Swiss Plus implant fixtures were taken in Afnor type artificial saliva solution at $37^{\circ} \mathrm{C}$. The concentration of ions leached into artificial saliva solutions was estimated with ICP-MS. SEM images of the margins of suprastructure/implant couples were obtained before and after the electrochemical tests. Results: The OCP value of titanium became passive at the most negative potential. The lowest difference between the initial and constant OCP value was exhibited by the Au based suprastructure. Suprastructures made greater contributions to the potentiodynamic polarization curves of the implant/ suprastructure couples. According to the ICP-MS results, Pd based and Au based couples dissolved less than Co-Ni based and Co$\mathrm{Cr}$ based couples. Conclusions: Within the conditions this study, it may be concluded that the titanium implant forms a stable passive oxide layer in artificial saliva exposed to open air and does not affect the corrosion properties of the suprastructures. Pd based and Au based couples have been found to be more corrosion-resistant than base alloy couples.
\end{abstract}

Key words: Corrosion. Dental casting alloys. Titanium implant. Electrochemical properties. Galvanic corrosion.

\section{INTRODUCTION}

Dental implants and abutments are generally produced from titanium because of its well documented biocompatibility and mechanical properties ${ }^{1}$. While the quality of implant materials made of titanium is unanimously acknowledged, the selection of suitable alloys for suprastructure is open to discussion. This selection must be done by considering the given alloy's resistance to corrosion when coupled with titanium, its biocompatibility, and the existing clinical studies of the relation between the metals and epithelial/subepithelial connective tissues ${ }^{21}$.

A galvanic current occurs when different metals come into contact with each other in an electrolytic medium, resulting in corrosion. The intensity of the galvanic current depends on different factors such as the electrode potential, polarization, surface area ratio of anode/cathode, distance between the electrodes, structure of the electrode surface, aeration, temperature, $\mathrm{pH}$ and composition of the electrolyte. In addition, there are some corrosion types to be taken into account, like the occurrence of crevice corrosion originating from its geometry ${ }^{17,21}$. Depending on the electrode potentials of the metals in the electrolytic medium, one acts as the anode and the other as the cathode. The more noble metal is the cathode and the more active one is the anode. Thus, a corrosion cell is formed. Only the anode goes into corrosion in this cell. In some cases, corrosion is expected, but in practice, the reaction does not occur or occurs at a very slow rate due to the formation of a passive layer. The corrosion rate of some metals is considerably low by reason of this passive layer formation.

Oral galvanism takes place when there is a difference in the electrical potential between dissimilar restorative metals ${ }^{5}$. With metals and alloys, corrosion is always accompanied by ion release and a current. When the materials in the oral cavity undergo corrosion, deterioration occurs in the mechanical and aesthetic properties. More importantly, corrosion products have local or systemic adverse effects on biological structures ${ }^{23,26}$. Besides, the current resulting from the galvanizing couple can cause bone resorption ${ }^{7,14,19}$. The 
extended presence of corrosion reactions can result in fractures at the interface of the alloy and abutment. Some researchers have reported that high stress concentrations between the suprastructure-implant interfaces may be responsible for implant failure and the stress corrosion fractures there may evolve $^{13,24}$. The effects of galvanic corrosion over short or long periods could be decreased with the use of the appropriate suprastructure alloy ${ }^{13}$. It can be said that, in the ideally selection of an suprastructure alloy, the alloy should not cause galvanic corrosion when coupled with titanium therefore no ion release occur because of the galvanic corrosion at the titanium implant or at the alloy.

Even though numerous studies have been conducted, all of the mechanisms involved in such corrosion are not yet completely understood ${ }^{12}$. On the one hand, in vivo evaluations are not reproducible; on the other hand, the physiological conditions of in vitro experiments cannot be fully simulated. In order to measure how corrosion-resistant dental alloys are qualitatively, electrochemical tests such as open circuit potential measurements and potentiodynamic polarization tests can be used ${ }^{15}$. The potentiodynamic polarization technique used mostly in corrosion tests is an in vitro method ${ }^{8}$. Electrochemical potentiodynamic polarization techniques are often used, providing general information about the corrosion resistance and susceptibility, such as the general corrosion rate, the range of passivation, and the break-down potential. In these methods, corrosion curent (Icorr) and potential (Ecorr) can be obtained by extrapolating the anodic and cathodic branches of potentiodynamic polarization curves. Electrochemical methods have been successfully implemented in several investigations of various corrosion problems in dentistry.

The aim of this in vitro study was to investigate and compare the electrochemical interaction of four different commercially available dental casting alloys when used as implant suprastructure, while coupled with titanium implant.

\section{MATERIAL AND METHODS}

In this study, 4 straight SwissPlus (Sulzer Dental Inc., Carlsbad, CA, USA) implant fixtures $10 \mathrm{~mm}$ in length, 4.1 $\mathrm{mm}$ in diameter and $4.8 \mathrm{~mm}$ in platform diameter were coupled with four UCLA type suprastructures made of four different commercial dental alloys. The cervical regions of the implants had a $2.5 \mathrm{~mm}$ high machined surface and 0.6 $\mathrm{mm}$ high beveled shoulders. The suprastructures and suprastructure/implant couples were named as M1, M2, M3, M4 and C1, C2, C3, C4, respectively.

Four cylindrical UCLA type suprastructures with a length of $6.5 \mathrm{~mm}$ and a diameter of $4.8 \mathrm{~mm}$ were obtained by using Swiss Plus plastic waxing coping (Sulzer Dental Inc.) from four different types of dental alloy. Table 1 shows the types and composition of the samples used. Each pattern was invested and melted in an induction casting machine (Bego Fornax 35 EM, Bremer, Germany), based on recommendations of the alloy manufacturers. All casts were sandblasted to remove the oxide films and residual investments. Finishing and polishing were done using light pressure under standard conditions with a high speed polishing motor. The polishing was completed using a soft brush and a $1-\mu \mathrm{m}$ polishing paste. The specimens were washed in distilled water and ultrasonically cleaned in ethanol. The suprastructure samples were screwed into the fixtures using a manual torque wrench with a force of $30 \mathrm{Ncm}$.

The $1.5 \mathrm{~mm}$ thick copper wire was cleaned using concentrated nitric acid, and then covered with polymethyl methacrylate resin. The clamp shaped copper wire with both its tips open and covered with resin was resistant to distortion and also slightly flexible. The gap between the two ends of the resin coated copper wire was $3 \mathrm{~mm}$ shorter than the coupled samples (Figure 1a). The coupled samples were tightened between the two ends of the copper wire. In this way, an electrical connection between the two ends of the sample was formed. Finally, the uncovered copper, the top of the cylindrical suprastructure and the MTX textured surface of fixture were covered with epoxy resin (Figure 1a).

TABLE 1- Chemical composition of materials used as weight $\%$

\begin{tabular}{|c|c|c|c|c|c|c|c|c|c|c|c|c|}
\hline Material & $\mathrm{Au}$ & Pt & Pd & $\mathbf{N i}$ & Co & $\mathrm{Cr}$ & $\mathrm{Cu}$ & Ga & In & Mo & $\mathrm{Zn}$ & Si \\
\hline M1 (Co-Ni based) & & & & 61 & & 26 & & & & 11 & & 1.5 \\
\hline ×M2 (Co-Cr based) & & & & & 64.8 & 28.5 & & & & 5.3 & & 0.5 \\
\hline “M3 (Pd based) & 2 & & 79 & & & & 6.9 & 5.5 & 4.5 & & & \\
\hline +M4 (Au based) & 85.9 & 11.7 & & & & & & & & & 1.5 & \\
\hline $\mathrm{Ti}$ & $\begin{array}{l}\text { Cold } \\
\text { (Ti=9 }\end{array}$ & $\begin{array}{l}\text { vorked } \\
, \mathrm{C}<0\end{array}$ & $\begin{array}{l}\text { grade } \\
1, \mathrm{H}<\end{array}$ & $\begin{array}{l}4 \mathrm{col} \\
.015\end{array}$ & $\begin{array}{l}\text { erciall } \\
e<0 .\end{array}$ & $\begin{array}{l}\text { pure } \\
\mathrm{N}<0\end{array}$ & 「i & $0.4)$ & & & & \\
\hline
\end{tabular}

\footnotetext{
$\mathrm{x}: \mathrm{Mn}+\mathrm{C}<1 \% ; \quad$ *: $\mathrm{Sn}+\mathrm{Zn}<\% 2 ; \quad{ }^{+}: \mathrm{Rh}+\mathrm{Ir}+\mathrm{Nb}+\mathrm{Mn}+\mathrm{In}+\mathrm{Fe}<\% 1$

M1 Remanium CS, Dentaurum, Ispringen, Germany.

M2 Biosil F, DeguDent GmbH, Hanau, Germany.

M3 Cerapall 2, Metalor Métaux Préciux SA, Neuchatel, Switzerland

M4 V-Gnathos ${ }^{\circledR}$ Plus, Metalor Métaux Préciux SA, Neuchatel, Switzerland

Ti SwissPlus ${ }^{\mathrm{TM}}$, Sulzer Dental Inc., Carlsbad. CA, USA
} 
a

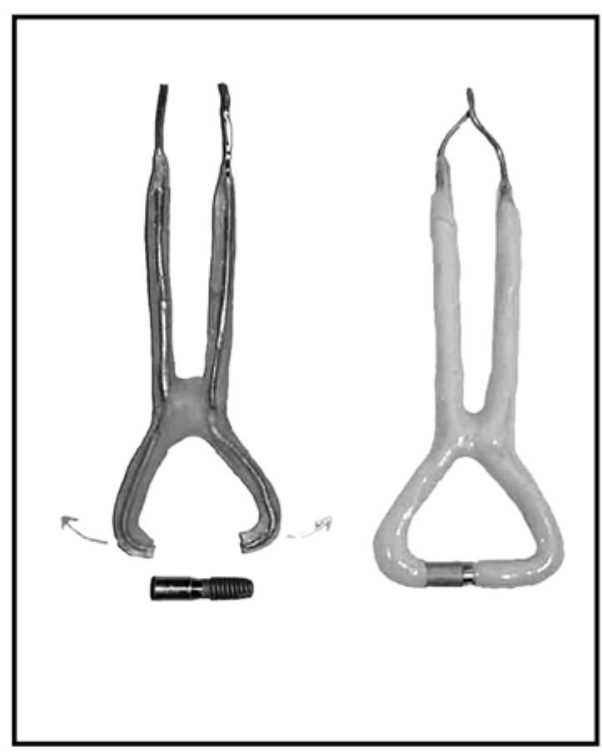

b

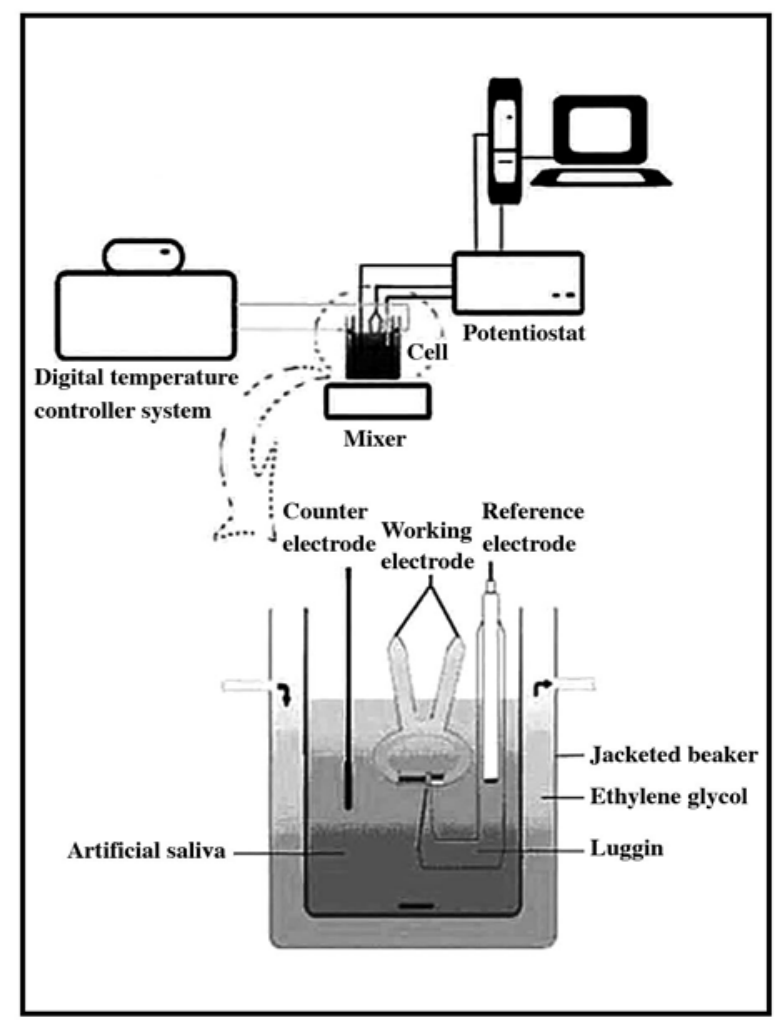

FIGURE 1- (a) Two tips open, flexible, copper clamp and covered sample with epoxy resin. (b) Schematic view of electrochemical cell and experiment set up

A jacketed beaker was used to maintain a constant temperature during the electrochemical measurements. The Afnor type ${ }^{6}$ artificial saliva solution $\left(\mathrm{K}_{2} \mathrm{HPO}_{4}: 0.2, \mathrm{KCl}: 1.2\right.$, KSCN: $0.33, \mathrm{Na}_{2} \mathrm{HPO}_{4}: 0.26 \mathrm{NaCl}: 0.7, \mathrm{NaHCO}_{3}: 1.5$, $\mathrm{CO}\left(\mathrm{NH}_{2}\right)_{2}: 1.5$ g.L. $\left.{ }^{-1}\right)$ buffered to 6.7 and exposed to open air was used as the electrolytic medium. A digital temperature controller system (Model 9602; Polysciences Inc., Warrington, PA, USA) was used to maintain the temperature of the system containing $125 \mathrm{~mL}$ of artificial saliva constant at $37^{\circ} \mathrm{C}$. A potentiostat-galvanostat system (System Model 660B; Ch Instruments Inc., Austin, TX, USA) was connected to a computer and used for the purposes of the study. The electrochemical measurements were carried out in a single compartment three-electrode cell with the prepared alloy as the working electrode $\left(1.33 \mathrm{~cm}^{2}\right)$, platinum foil $\left(1.00 \mathrm{~cm}^{2}\right)$ as the counter electrode and the saturated calomel electrode (SCE) as the reference electrode. The SCE was drawn about $2 \mathrm{~mm}$ from the working electrode with a capillary tip (Luggin capillary). The potential was applied between the reference and working electrode, and the resulting current between the working electrode and the counter electrode was recorded. The entire set up of the experiment is shown in Figure 1b.

Prior to the potentiodynamic polarization test, the samples underwent $10 \mathrm{~min}$ of electrolysis at a constant potential of $600 \mathrm{mV}$ so that the effects of oxides and other impurities on the surface would be eliminated. Potentiodynamic polarization curves were obtained between a $-800 \mathrm{mV}$ and $1600 \mathrm{mV}$ potential range with a scan rate of $1 \mathrm{mV} \mathrm{s}^{-1}$. Each experiment was performed with freshly prepared artificial saliva solution. At least three experiments were carried out in order to get similar potentiodynamic polarization curves for all of the samples.

After obtaining the potentiodynamic polarization curves of all samples coupled with titanium, the concentration of the ions that leached into the artificial saliva solutions was estimated with ICP-MS (Thermo Elemental X 7 ICP-MS, Winsford, England) in ppm (parts per million).

A scanning electron microscope (SEM) (JEOL JSM 6400, Jeol, Tokyo, Japan) was used to obtain images before and after the potentiodynamic polarization tests for the coupled samples, including the margins of the suprastructures and implants in order to determine resultant corrosion. All images were saved in a digital medium. Following the potentiodynamic polarization tests, the samples were washed several times with de-ionized water to remove any ions adsorbed to the surface and were kept in a nitrogen environment.

Following the SEM imaging, the suprastructures were removed from the implants, and cleaned and polished once again. The open circuit potential vs. time (nearly $14 \mathrm{~h}$ ) curves and potentiodynamic polarization curves of each sample were obtained separately for all the suprastructures and titanium under the same experimental conditions. 


\section{RESULTS}

1. Open-Circuit Potentials (OCP): Figure 2 shows the OCP versus time curves of the suprastructures and titanium recorded during $5.0 \times 10^{4}$ seconds in Afnor type solution at $37^{\circ} \mathrm{C}$. The OCP data obtained are summarized in Table 2.
2. The effect of the titanium and the suprastructure in the $\mathrm{Ti} /$ suprastructure couple on the potentiodynamic polarization curves: Figures 3a, b, c, d show the potentiodynamic polarization curves of Titanium (Ti), the suprastructures (M1, M2, M3, M4) and the Ti/suprastructure couples (C1, C2, C3, $\mathrm{C} 4)$ in Afnor type solution at $37^{\circ} \mathrm{C}$, respectively. According

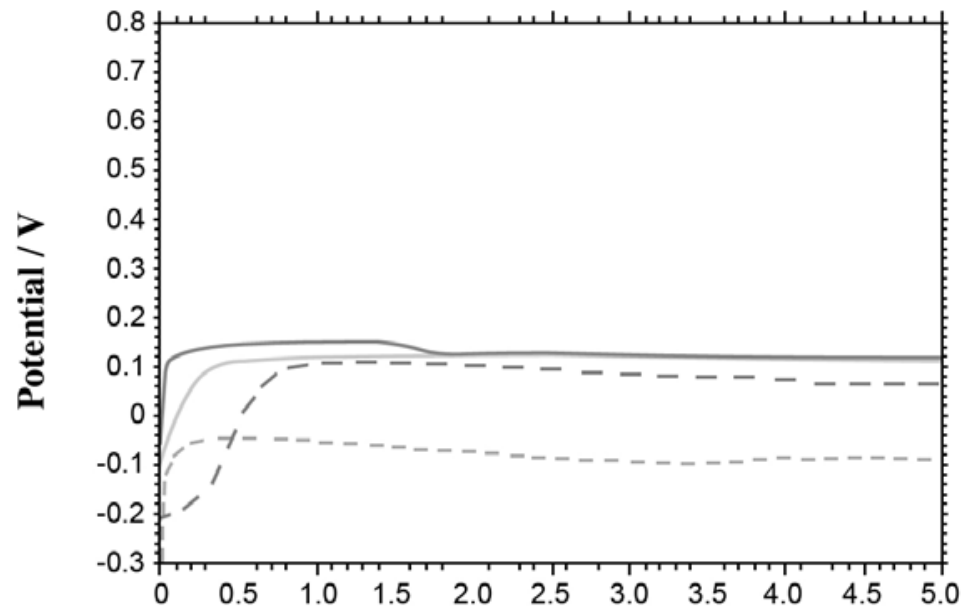

Time / 1e+4sec

FIGURE 2- Open circuit potential (OCP) versus time curves of suprastructures (M1, M2, M3, M4) and Ti recorded in Afnor type solution at $37^{\circ} \mathrm{C}$

a

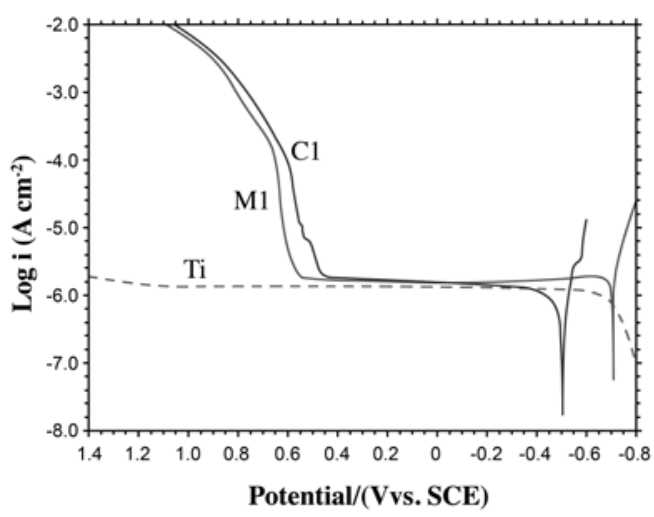

c

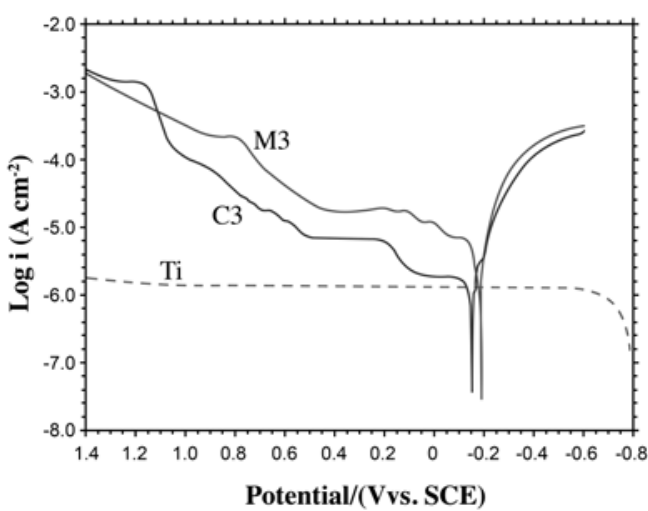

b

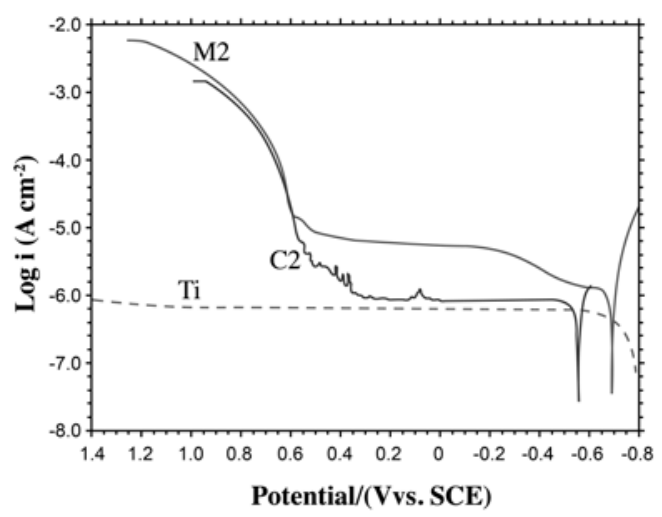

d

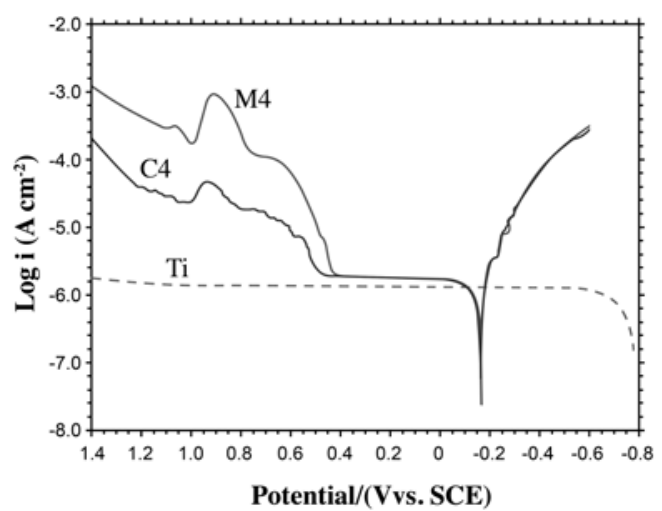

FIGURE 3- Potentiodynamic polarization curves at $37^{\circ} \mathrm{C}$ in Afnor type solution (scan rate: $1 \mathrm{mV} \mathrm{sec}^{-1}$ ). (a) M1, C1 and Ti (b) $\mathrm{M} 2, \mathrm{C} 2$ and $\mathrm{Ti}$ (c) M3, C3 and $\mathrm{Ti}(\mathrm{d}) \mathrm{M} 4, \mathrm{C} 4$ and $\mathrm{Ti}$ 
to these curves it was observed that suprastructures contribute more to the potentiodynamic polarization curves of the implant/suprastructure couples $(\mathrm{C} 1, \mathrm{C} 2, \mathrm{C} 3, \mathrm{C} 4)$ compared

TABLE 2- Open-circuit potentials data for $\mathrm{Ti}$ and the suprastructures

\begin{tabular}{lcc}
\hline Material & $\mathbf{E}_{\text {initial (mV) }}$ & $\mathbf{E}_{\text {constant (mV) }}$ \\
\hline M1 & -185 & 120 \\
M2 & -220 & 105 \\
M3 & -100 & 105 \\
M4 & 60.0 & 135 \\
Ti & -200 & -50.0 \\
\hline
\end{tabular}

to the potentiodynamic polarization curves of the suprastructures (M1, M2, M3, M4) and titanium (Ti) (Figures $3 \mathrm{a}, \mathrm{b}, \mathrm{c}, \mathrm{d}$ ) because no considerable rise at the anodic current branch of titanium was observed between $-60.0 \mathrm{mV}$ and 1200 $\mathrm{mV}$. The most important pitting potentials of the couples and their suprastructures are; $\mathrm{C} 1: 626 \mathrm{mV}, \mathrm{M} 1: 630 \mathrm{mV}$; 2 : 588 $\mathrm{mV}, \mathrm{M} 2: 601 \mathrm{mV}$; C3: 779, M3: $696 \mathrm{mV}$; C4: $521 \mathrm{mV}$, and M4: 530.

3. Comparison of the potentiodynamic polarization curves of the Ti/suprastructure samples: The potentiodynamic polarization curves of the couples $(\mathrm{C} 1, \mathrm{C} 2, \mathrm{C} 3$, and $\mathrm{C} 4)$ are shown in Figure 4. The $\mathrm{E}_{\text {corr }}$ and $\mathrm{E}_{\text {pitting }}$ potentials; $\mathrm{I}_{\text {corr }}$ and current values at $250 \mathrm{mV}, 800 \mathrm{mV}$ are also given in Table 3 as obtained from these curves.

4. Ion concentration leached into the solution from the $\mathrm{Ti} /$ suprastructure couples: After obtaining the

TABLE 3- Potential and current values obtained from potentiodynamic the polarization curves of Ti/suprastructure couples

\begin{tabular}{|c|c|c|c|c|c|}
\hline Sample & $\mathrm{E}_{\text {corr }} / \mathrm{mV}$ & $\mathrm{E}_{\text {pitting }} / \mathrm{mV}$ & $\mathrm{I}_{\text {corr }} / \mu \mathrm{A} \mathrm{cm} \mathrm{cm}^{-2}$ & $\mathrm{I}_{250 \mathrm{mv}} / \mu \mathrm{A} \mathrm{cm}^{-2}$ & $\mathrm{I}_{800 \mathrm{mv}} / \mu \mathrm{A} \mathrm{cm} \mathrm{cm}^{-2}$ \\
\hline $\mathrm{C} 1$ & -517 & 626 & 0.4341 & 1.222 & 1154 \\
\hline $\mathrm{C} 2$ & -568 & 588 & 0.7502 & 1.297 & 2986 \\
\hline $\mathrm{C} 3$ & -160 & 140,779 & 0.7086 & 5.012 & 25.87 \\
\hline $\mathrm{C} 4$ & -171 & 521 & 0.5522 & 1.236 & 12.54 \\
\hline
\end{tabular}

TABLE 4- Concentration of the ions leached into the artificial saliva solutions from the Ti/suprastructure couples

\begin{tabular}{lll}
\hline Sample & Individual ion concentrations/ppm & Total \\
\hline C1 & Ni: $0.950 ; \mathrm{Cr}: 0.399 ; \mathrm{Mo:} 0.214 ; \mathrm{Si}:-$ Ti: 0.184 & 1.75 \\
C2 & Co: $1.21 ; \mathrm{Cr}: 0.479 ; \mathrm{Mo:} 0.122 ; \mathrm{Mn}: 0.011 ; \mathrm{Si}:(-) ; \mathrm{Ti:} 0.181$ & 2.01 \\
C3 & Au: $0.002 ; \mathrm{Pd}: 0.048 ; \mathrm{Cu}: 0.011 ; \mathrm{Sn}: 0.016 ; \mathrm{Ga}:(-) ; \mathrm{In}:(-) ; \mathrm{Ti}: 0.179$ & 0.256 \\
C4 & Au: $0.038 ; \mathrm{Pt}: 0.006 ; \mathrm{Rh:} 0.001 ; \mathrm{Zn:}(-) ; \mathrm{Ti}: 0.182$ & 0.227 \\
\hline
\end{tabular}

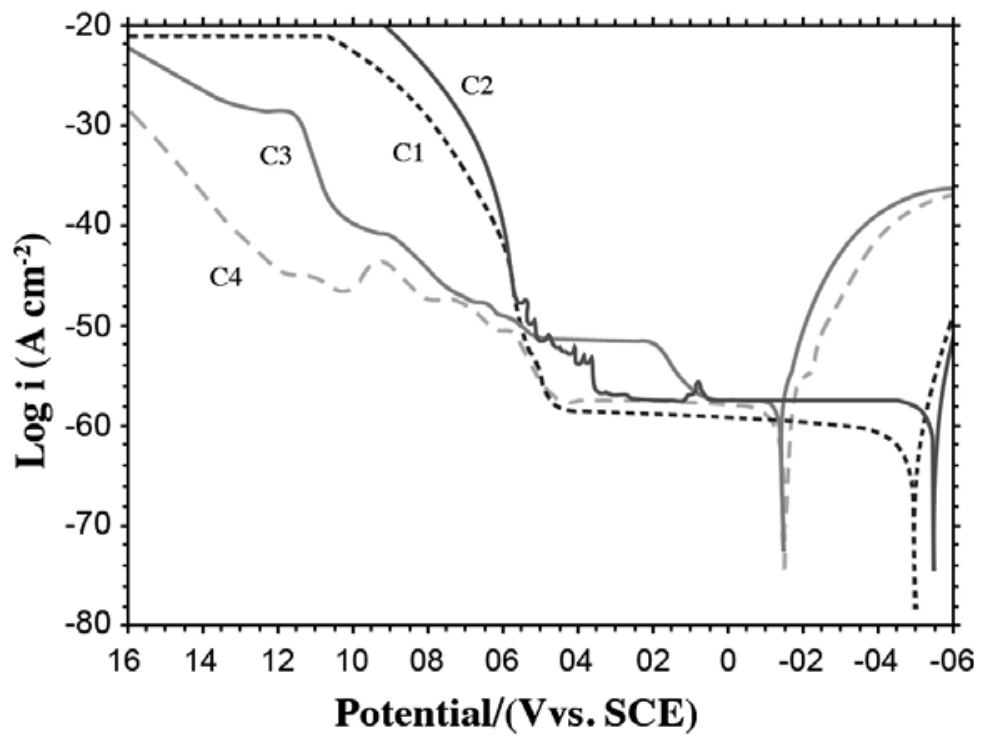

FIGURE 4- Potentiodynamic polarization curves of $\mathrm{C} 1, \mathrm{C} 2, \mathrm{C} 3$ and $\mathrm{C} 4$ at $37^{\circ} \mathrm{C}$ in Afnor type solution (scan rate: $1 \mathrm{mV}^{\text {sec }}{ }^{-1}$ ) 

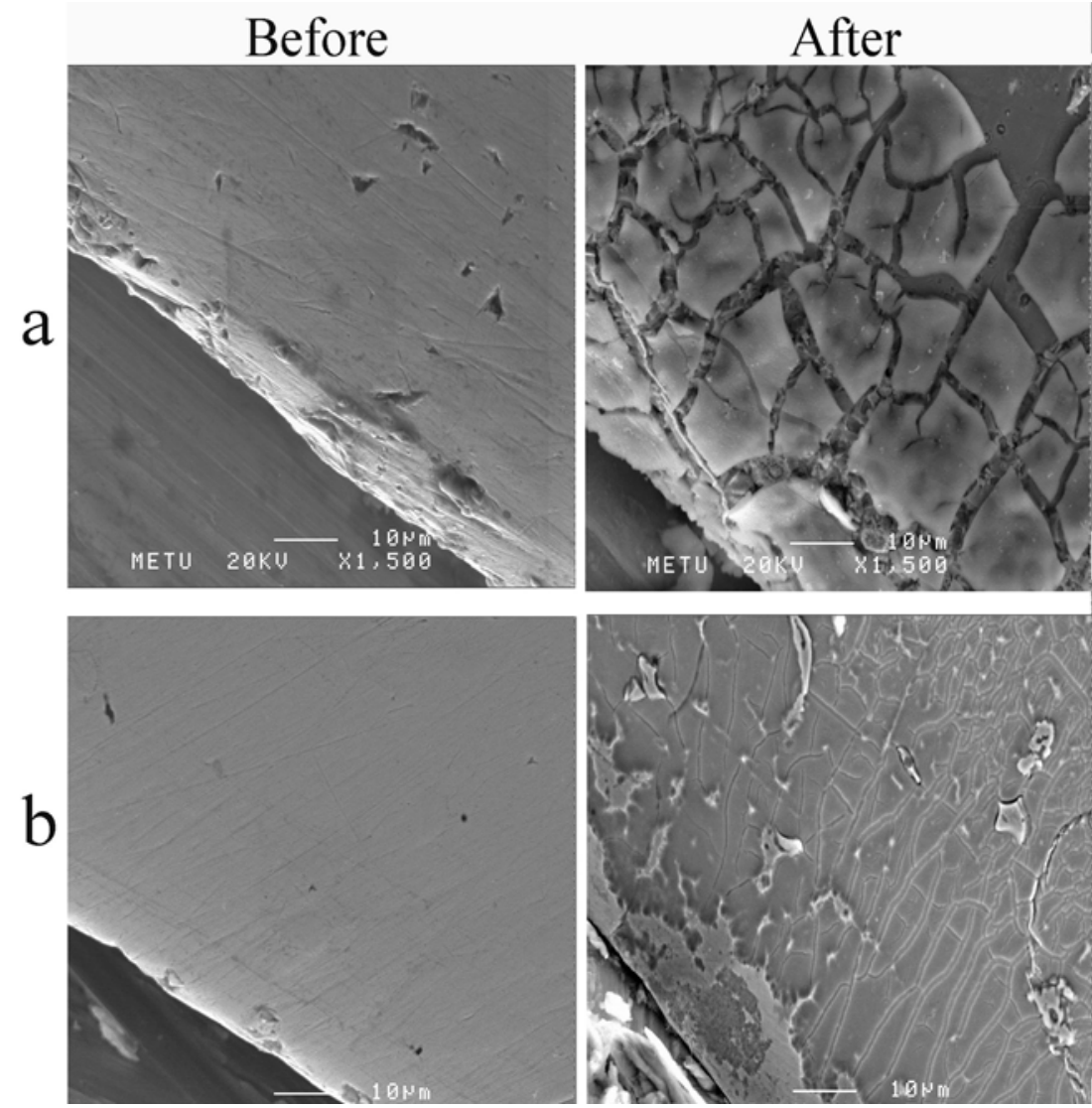

FIGURE 5- SEM images; before and after the potentiodynamic polarization tests (a) C1 (b) C2
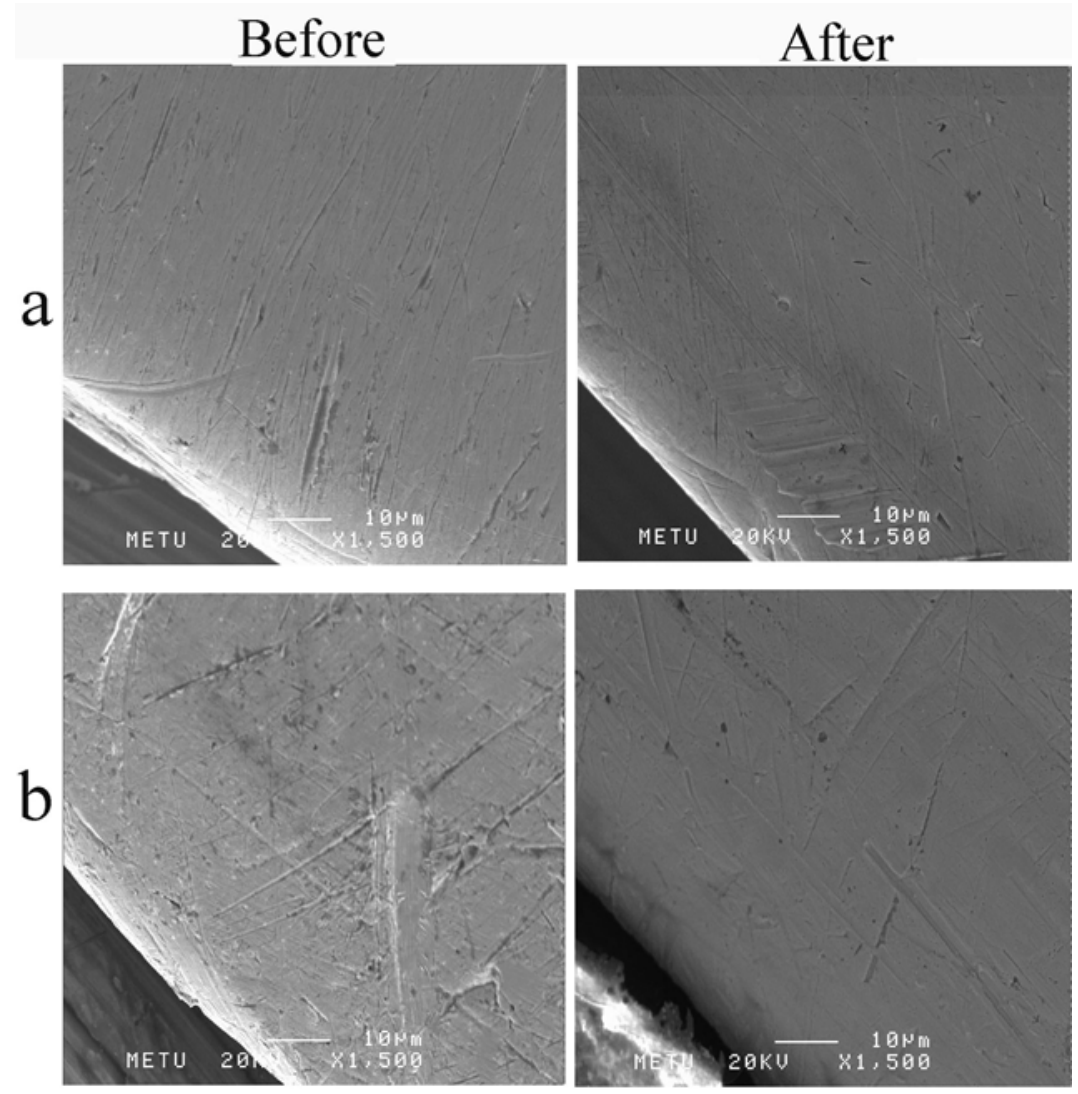

FIGURE 6- SEM images; before and after the potentiodynamic polarization tests (a) C3 (b) C4 
potentiodynamic polarization curves of the samples coupled with titanium, the concentration of the ions that leached into the artificial saliva solutions were estimated with ICP-MS and are illustrated in Table 4.

5. SEM Images: When SEM images taken before and after potentiodynamic polarization curves were compared, extensive breakdowns was observed at surface of the suprastructures of samples $\mathrm{C} 1$ and $\mathrm{C} 2$. It was clearly observed that segregations extensively observed on the whole surfaces, however there were still little unaffected areas could be detected appearing as weakly attached to the surface (Figures $5 \mathrm{a}, \mathrm{b})$. When surfaces of $\mathrm{Ti}, \mathrm{C} 3$ and $\mathrm{C} 4$ materials were investigated, almost no visible effect was revealed (Figures $6 a, b)$.

\section{DISCUSSION}

In this study, UCLA type abutment was used to connect a titanium implant body directly to a suprastructure. With UCLA type abutment implants, removable crowns can be attached directly to the bodies of the implants by using screws $^{9,29}$. A disadvantage while using this type of abutment is the possibility of corrosion due to the connection of two different metals and fitting problems resulted at casting ${ }^{29}$.

The resistance a metal or an alloy exhibits against corrosion depends not only on its own properties but also on its interactions with its surroundings ${ }^{4}$. When metals and alloys are exposed to high temperature $\left(0.0^{\circ} \mathrm{C}-70^{\circ} \mathrm{C}\right)$, such as during eating, their $\mathrm{pH}$ changes $(2-11)^{10}$. As opposed to liquids in other types of tissue, the concentration of electrolyte and oxygen in the oral cavity varies. For this reason; dental implants, open to the oral cavity, are more exposed to galvanic corrosion than orthopedic implants ${ }^{13}$. Moreover, saliva is exposed to open air, which contains gases like $\mathrm{SO}_{\mathrm{x}}, \mathrm{NO}_{\mathrm{x}}$, chlorides, oxygen and sulfide, resulting in atmospheric corrosion $^{22}$.

In biomedical applications, titanium is known to have good corrosion properties because of the stable, smooth and strongly adherent passive oxide film forming rapidly on the metal surface ${ }^{3}$ when the oxide layer brakes down mechanically. Since resistance to corrosion is directly proportional to the oxide layer formation, a strong passive film formation on the metal surface enhances resistance to corrosion. It follows from this that the worst situation is the prevention of passive layer formation for a biomedical metallic material. The concentration of the metal ions released into the solution is related to the nature, composition and thickness of the metal oxides and adherence force to the alloy ${ }^{18}$.

Information about the general interaction at the surface of the alloy can be obtained by evaluating the changes at open circuit potential values. OCP curve values shifting towards to positive potentials show that the oxidation current of the alloy will reduce and form a passive surface layer. Shifting the values of the curve towards to more negative potential indicates that the oxidation current density gradually increases, in other words ion release is taking place. The potential becomes constant against time and this behavior shows that electrochemical reactions at the alloy surface are in equilibrium. In this study, the potential of all samples shifted to more positive values and became constant after a period of time (Figure 2, Table 2). The surface of the titanium became passive at the most negative potential. The open circuit potentials of M1 and M2 became constant after 280 and 145 min because of the slowly forming unstable oxide layer. On the other hand, M3 and M4 had open circuit potentials constant at 65 and $50 \mathrm{~min}$, respectively. With the smallest difference between the constant and initial open circuit potential values, M4 was found to be the most suitable suprastructure alloy in the alloys tested in this study.

According to the ICP-MS results, the titanium concentration transferring to the solution from all of the $\mathrm{Ti} /$ suprastructure couples was the almost the same. The investigation of the total ion concentrations leached into the artificial saliva solution shows that $\mathrm{C} 3(0.256 \mathrm{ppm})$ and $\mathrm{C} 4$ $(0.227 \mathrm{ppm})$ dissolved less than the base alloys, C1 (1.75 ppm) and $\mathrm{C} 2(2.01 \mathrm{ppm})$ while the potentiodynamic polarization curves were being obtained (Table 4). These results are in accordance with those of the potentiodynamic polarization curves. This is because $\mathrm{C} 3(79 \% \mathrm{Pd})$ and $\mathrm{C} 4$ $(86 \% \mathrm{Au})$ contain large amounts of noble metals. On the other hand, the $\mathrm{C} 1$ and $\mathrm{C} 2$ base alloys were made up of $\mathrm{Ni}$, $\mathrm{Cr}$ and $\mathrm{Co}, \mathrm{Cr}$ respectively. It can also be said that because of the unstable oxide layer composition, a larger ion concentration transferred to the solution from the $\mathrm{C} 1$ and C2 suprastructure alloys.

The corrosion current and corrosion potential were determined by extrapolation of the linear portions of the anodic and cathodic potentiodynamic polarization curves ${ }^{27}$. When a comparison was made between the potentiodynamic polarization curves of the suprastructures (M1, M2, M3, M4) and titanium implant (Ti) with those of the implant/ suprastructure couples $(\mathrm{C} 1, \mathrm{C} 2, \mathrm{C} 3, \mathrm{C} 4)$, it was observed that the contribution to the couples was mostly from the suprastructure (Figs. 3a, b, c, d). This was because the anodic current density of the titanium implant had a very small value at higher potentials and no rise was observed at the anodic branch. Although titanium has a negative corrosion potential value $\left(\mathrm{E}_{\text {corr }}\right)$, its surface is covered with oxide layers $\left(\mathrm{TiO}_{2}\right.$ and a small amount of $\mathrm{Ti}_{2} \mathrm{O}_{3}$ and $\mathrm{TiO}$ ), protecting it against corrosion $^{10}$. These results are consistent with those of previous studies on the formation of a passive layer on the titanium surface, which increases corrosion strength ${ }^{20}$.

The $\mathrm{E}_{\text {corr }}$ values of $\mathrm{C} 3$ and $\mathrm{C} 4(-160 \mathrm{~V}$ and $-171 \mathrm{~V})$ were found to be at more positive values than those of $\mathrm{C} 1$ and $\mathrm{C} 2$ (-517 V and $-568 \mathrm{~V})$. The current densities of $\mathrm{C} 3$ and $\mathrm{C} 4$ also had low values at $800 \mathrm{mV}$ when compared with those of the other samples because of the noble metals present in C3 (79\% Pd) and C4 (86\% Au) (Table 3). These results show that $\mathrm{C} 1$ and $\mathrm{C} 2$ are weaker materials when their corrosion performance is compared. The total ion concentration passing onto the solution from $\mathrm{C} 1$ and $\mathrm{C} 2$ showed that they had dissolved more than the other alloys, which is in agreement to the above result. The nickel and cobalt present in the structure of $\mathrm{C} 1$ formed a complex with 
the thiocyanate ion from saliva, and nickel could make complexes or compounds with urea ${ }^{16,28}$. Thus, the formation of complexes and compounds could contribute to the weakness of the alloys.

When the ICP-MS and $\mathrm{E}_{\text {corr }}$ values of $\mathrm{C} 1, \mathrm{C} 2, \mathrm{C} 3$ and $\mathrm{C} 4$ were compared, it was expected that $\mathrm{C} 3$ and $\mathrm{C} 4$ would have lower current values at $250 \mathrm{mV}$ and $800 \mathrm{mV}$ (Table 3 ). Another reason for this expectation was the fact that $\mathrm{C} 3$ and $\mathrm{C} 4$ have large amounts of noble metals, palladium and gold, respectively. When dissolving total ion concentrations were compared, C3 was found as one of the alloys showing least dissolution $(0.256 \mathrm{ppm})$. In addition, when the values of $\mathrm{E}_{\text {corr }}$ were compared, $\mathrm{C} 3$ was observed to oxidize at the most positive potential. In contrast to these results, $\mathrm{C} 3$ started to dissolve at $140 \mathrm{mV}$ and had a current value of $250 \mathrm{mV}$, which was higher than expected. This could be due to the presence of the small amount of $\mathrm{Cu}$ and $\mathrm{Sn}$, making the alloy vulnerable to corrosion even though it contains high amounts of a noble metal like palladium. The presence of the small amount of $\mathrm{Cu}$ in the alloy prevents the material from being resistant against corrosion. Bayramoglu et al also mentioned in their study that titanium dissolves less because of its oxide layer while $\mathrm{Sn}$ and $\mathrm{Cu}$ containing alloys dissolve more ${ }^{2}$.

In this study, the sample $\mathrm{C} 4$ with Au was found to have dissolved the least according to the ICP-MS results, which was parallel with the results of the electrochemical test. C4 seems to have dissolved less when a comparison was made in terms of the $\mathrm{I}_{800 \mathrm{mV}}$ values. The SEM images of C4 also support these data (Figure 5b). However, the potassium thiocyanate present in the saliva solution in high concentrations is a disadvantage ${ }^{25}$. Gold in $\mathrm{C} 4$ could form a complex with thiocyanate ions, posing a problem, as also reported for these types of solutions ${ }^{11}$. Even beginning to dissolve at a more negative potential $\left(\mathrm{E}_{\text {pitting }}=521 \mathrm{mV}\right)$, which is a disadvantage for gold containing samples in artificial saliva solution, this sample was concluded to be superior to the others since it had dissolved less $\left(\mathrm{I}_{800 \mathrm{mV}}=12.54 \mu \mathrm{A} \mathrm{cm}^{2}\right)$. The low current density at $800 \mathrm{mV}$ also confirmed that it was superior material comparing to the others. In conclusion, the formation of complexes with thiocyanate ion could contribute to the weakness of the $\mathrm{C} 4$ suprastructure alloy, but this alloy was appeared superior in terms of resistance to corrosion among the samples tested.

A comparison of the SEM images taken before and after the potentiodynamic polarization tests showed that the surfaces of the $\mathrm{C} 1$ and $\mathrm{C} 2$ suprastructures were extremely prone to corrosion. It was seen that the aggregations weakly attached to the surface had fallen off, and a strong presence of metal was observed (Figures 5a,b). The segregations on the surface of the alloys showed that the corrosion had started from the grain boundaries. On the other hand, no significant change was observed in the SEM images of Ti, C3 and C4 before and after corrosion (Figures 6a,b).

\section{CONCLUSIONS}

Under the circumstances of this in vitro experimental study it may be concluded that: 1 . The titanium implants rapidly formed a stable, passive layer. 2 . In the titanium implant and suprastructure alloy combinations, the titanium implant had virtually no effect on the pitting potential due to the passive layer formed on the surface of the implant. The corrosion properties were highly related to the suprastructure alloys. 3. The gold and palladium-based, noble alloys were found to have dissolved less than the nickel-chromium and cobalt-chromium alloys.

\section{REFERENCES}

1 - Adell R, Lekholm U, Rockler B, Branemark PI. A 15-year study of osseointegrated implants in the treatment of the edentulous jaw. Int J Oral Surg. 1981;10(6):387-416.

2- Bayramoglu G, Alemdaroglu T, Kedici S, Aksut AA. The effect of pH on the corrosion of dental metal alloys. J Oral Rehabil. 2000;27(7):56375 .

3- Berg E, Wagnere WC, Davik G, Dootz ER. Mechanical properties of laser-welded cast and wrought titanium. J Prosthet Dent. 1995;74(3):2507 .

4- Bergman M. Corrosion in the oral cavity: potential local and systemic effects. Int Dent J. 1986;36(1):41-4.

5- Certosimo AJ, O’Connor RP. Oral electricity. Gen Dent. 1996;44(4):324-6.

6- Cortada M, Giner L, Costa S, Gil FJ, Rodriguez D, Planell JA. Galvanic corrosion behavior of titanium implants coupled to dental alloys. J Mater Sci Mater Med. 2000;11(5):287-93.

7- Geis-Gerstorfer J, Weber H, Sauer KH. In vitro substance loss due to galvanic corrosion in $\mathrm{Ti}$ implant/Ni-Cr supraconstruction systems. Int $\mathrm{J}$ Oral Maxillofac Implants. 1989;4(2):119-23.

8- Holland RI. Corrosion testing by potentiodynamic polarization in various electrolytes. Dent Mater. 1992;8(4):241-5.

9- Jaime APG, Vasconcellos DK, Mesquita AMM, Kimpara ET, Bottino MA. Effect of cast rectifiers on marginal fit of UCLA abutments. J Appl Oral Sci. 2007;15(3):169-74.

10- Kedici SP, Aksut AA, Kilicarslan MA, Bayramoglu G, Gokdemir K. Corrosion behaviour of dental metals and alloys in different media. J Oral Rehabil. 1998;25(10):800-8.

11- Kononova ON, Kholmogorov AG, Danilenko NV, Kachin YS, Kononov YS, Dmitrieva ZV. Sorption of gold and silver on carbon adsorbents from thiocyanate solutions. Carbon. 2005;43:17-22.

12.- Laurent F, Grosgogeat B, Reclaru L, Dalard F, Lissac M. Comparison of corrosion behaviour in presence of oral bacteria. Biomaterials. 2001;22(16):2273-82.

13- Lemons JE, Dietsh-Mish F. Biomaterials for dental implants. In: Misch CE. Contemporary implant dentistry. St Louis: Mosby; 1999. p. 271-302.

14- Lucas LC, Lemons JE. Biodegradation of restorative metallic systems. Adv Dent Res. 1992;6:32-7. 
15- Mareci D, Nemtoi G, Aelenei N, Bocanu C. The electrochemical behaviour of various non-precious $\mathrm{Ni}$ and $\mathrm{Co}$ based alloys in artificial saliva. Eur Cell Mater. 2005;10:1-7.

16- Mavis B, Akin M. Kinetics of urea decomposition in the presence of transition metal ions: Ni2+. J Am Ceram Soc. 2006;89:471-7.

17- Oh KT, Kim KN. Electrochemical properties of suprastructures galvanically coupled to a titanium implant. J Biomed Mater Res B Appl Biomater. 2004;70(2):318-31.

18- Okazaki Y, Gotoh E. Comparison of metal release from various metallic biomaterials in vitro. Biomaterials. 2005;26(1):11-21

19- Olmedo D, Fernandez MM, Guglielmotti MB, Cabrini RL. Macrophages related to dental implant failure. Implant Dent. 2003;12(1):75-80.

20- Ravnholt G. Corrosion current and $\mathrm{pH}$ rise around titanium coupled to dental alloys. Scand J Dent Res. 1988;96(5):466-72.

21- Reclaru L, Meyer JM. Study of corrosion between a titanium implant and dental alloys. J Dent. 1994;22(3):159-68.

22- Schweitzer PA. Corrosion engineering handbook. New York: Marcel Dekker Inc; 1996 p. 167

23- Sun ZL, Wataha JC, Hanks CT. Effects of metal ions on osteoblastlike cell metabolism and differentiation. J Biomed Mater Res. 1997;34(1):29-37.

24- Tagger Green N, Machtei EE, Horwitz J, Peled M. Fracture of denta implants: literature review and report of a case. Implant Dent. 2002;11(2):137-43

25- Tsuge K, Kataoka M, Seto Y. Cyanide and thiocyanate levels in blood and saliva of healthy adult volunteers. J Health Sci. 2000;46:343-50

26- Wataha JC. Alloys for prosthodontic restorations. J Prosthet Dent. 2002;87(4):351-63.

27- Yagan A, Ozcicek Pekmez N, Yýldýz A. Electropolymerization of poly $(N$-ethyl aniline) on mild steel: synthesis, characterization and corrosion protection. Electrochim Acta. 2006;51:2949-55

28- Yang H, Whitten JL. Chemisorption of OCN on Ni(100): an ab initio study. Surf Sci. 1998;401:312-21.

29- Yildirim M, Edelhoff D, Hanisch O, Spiekermann H. Ceramic abutments: a new era in achieving optimal esthetics in implant dentistry. Int J Periodontics Restorative Dent. 2000;20(1):81-91. 